\title{
The importance of developing sustainable eco-aquaculture in a coastal area of China
}

\author{
K. K. L. Yung ${ }^{1}$ Ho Man Homan Leung ${ }^{1}$
}

Received: 10 February 2017 / Accepted: 22 February 2017 / Published online: 3 April 2017

(C) Springer-Verlag Berlin Heidelberg 2017

Hong Kong is located in the zone of Pearl River Delta (PRD) which is a very important place for agricultural, commercial, and industrial developments to the economy of Guangdong, China. According to the data provided by the Hong Kong Government (2017), the estimated local production of fish and fishery products and its imported products are 145,193 t. Thus, the aquaculture fishery industry in Hong Kong which consists of fish ponds and marine fish culture zones accounted for high production each year. However, various kinds of industries have moved to the rural area where having less stringent rules in treating the waste water. As a result, most of the industrial waste water is allowed to release directly to the nearby water bodies without any treatment. As Hong Kong and mainland China residents are the long-term chronic exposure to rather high levels of these toxic metals contained in food such as fish and vegetables, the safe consumption of aquatic food products continues to be a growing concern. For example, flame retardants such as polybrominated diphenyl ethers (PBDEs) were commonly found in the market fish, Hong Kong (Wang et al. 2011). PBDEs are endocrine disruptors and deteriorated the metabolisms found in different organ systems in human such as nervous, reproductive, and immune system and the pollutant tends to accumulate and magnify in an ecosystem. Besides, heavy metals such as

Responsible editor: Philippe Garrigues

K. K. L. Yung

kklyung@hkbu.edu.hk

1 Department of Biology, Hong Kong Baptist University, Kowloon Tong, Hong Kong mercury in the form of methylmercury $(\mathrm{MeHg}$ ) tend to bioaccumulate in the tissue of fish and shellfish and can be taken up by consumers of these foods (Wang et al. 2013). In expecting mothers, $\mathrm{MeHg}$ can easily pass through the placenta and affect the fetus resulting in neurological damage. In males, studies have shown that the consumption of fish contaminated by $\mathrm{MeHg}$ was correlated with subfertility. Other possible types of pollutants included pharmaceuticals, disinfectants, pesticides, fertilizers, and hormones were found in the fisheries and aquatic products.

In order to safeguard environment and health with regard to the production and consumption of aquatic products, there is an increasing demand for high quality, environmentally-friendly and safe aquaculture products. In addition, it is important to eliminate or mitigate the environmental impacts of aquaculture (especially along coastal areas) as this could lead to sediment contamination, water contamination, hypoxia, eutrophication, red tides, and harmful algae blooms. Thus, improved aquaculture technologies and management systems should be utilized that adopt holistic and symbiotic approaches. A healthy and sustainable eco-aquaculture industry should give overall consideration to population, market, quality, resources, and environment to ensure the sustainable development of eco-aquaculture based on the ecosystem carrying capacity. The practice of eco-aquaculture takes into account a number of environmental-friendly and eco-friendly factors included (1) closed, recirculating and low discharge systems; (2) mitigation of negative effects to local wildlife (plants as well as animals) and biodiversity; (3) prohibit of using genetically engineered fish or feed; (4) uses stocking densities that minimize the risk of disease outbreaks and transmission; (5) does not deplete local resources such as drinking water 
supplies, mangrove forests; and (6) supports the longterm economic and social well-being of local communities.

For this special issue of Environmental Sciences and Pollution Research (ESPR), entitled "Eco-aquaculture, sustainable development and public health," contributions were solicited from those who had made an oral or poster presentation at an "International Conference on Eco-aquaculture and Public Health (ICEAPH)," held on 28-30th November 2014 at Hong Kong Baptist University, Hong Kong where scientists working on the aquaculture and ecology were invited to report on their most recent results. Discussion topics included the current status of spatial and temporal pattern, distribution and ecotoxicological effects of inorganic and organic contaminants in the aquaculture (fresh and marine water); the health risk due to the consumption of contaminated fish cultivated in such area; and the possible evolution of using environmental friendly material such as algae due to the overuse of artificial coloring agents in aquacultural practice.

This special issue contains a collection of 22 publications from research institutions more than 10 cities. The authors discuss important problems, basic approaches, and new eco-aquaculture technology relevant to the topic in an attempt to provide a platform whereby people can present and discuss how innovative ecoaquaculture technology could be implemented and utilized to promote such environmental sound technology. It is envisaged that the information gathered in this special issue will serve as a valuable reference for the promotion of eco-aquaculture industries in Pearl River Delta (PRD), South China (including Hong Kong) and for achieving environmental, economical, and social development in a balanced way.

The articles in this special issue on eco-aquaculture, sustainable development, and public health are grouped into three sections as described below. For full article titles and authors, please refer to the table of contents.

\section{Recent development of terrestrial and marine ecosystems in China}

Seven publications report the background information of inorganic and organic pollutants in China on terrestrial and marine habitat based on monitoring data. Many articles originated from the coastal area of China and reflect the pollution status with distinct recent and economic and industrial development.

\section{Biological treatments of polluted water and soil}

Eleven publications assess the possible methods to understand biological process in order to decontaminate the polluted water and soil in aquaculture. This knowledge provides a basis for fostering more environmentally compatible eco-aquaculture operations.

\section{Management of the aquaculture by-products after remediation}

Three research articles and one review deal generally with byproducts after remediation in order to achieve the goal of sustainable development in eco-aquaculture.

As touched upon by several professionals in this special issue, it provides an insight to much wider discussions on the topic of eco-aquaculture, sustainable development, and public health in future.

The guest editors sincerely thank financial support from the Croucher Foundation and Mr. David Foster for the conference entitled "International Conference on Eco-aquaculture and Public Health" held on 28-30th November 2014 at Hong Kong Baptist University, Hong Kong. We very much acknowledge the invitation and support by the ESPR Editorin-Chief Philippe Garrigues, and help by the ESPR Editors Angeles Blanco, Bincai Pan, Cinta Porte, Elena Maestri, Ester Heath, Gerald Thouand, Roland Kallenborn, Xu Zhihong, and by the Editorial Assistants Géraldine Billerot, Laure Beugnot, and Marianne Salaün during the preparation of this special issue.

\section{References}

Hong Kong Government (2017) Hong Kong Year Book. Chapter 9. Hong Kong Special Administration Region, China.

Wang HS, Du J, Ho KL, Leung HM, Lam MHW, Giesy JP, Wong CKC, Wong MH (2011) Exposure of Hong Kong residents to PBDEs and their structural analogues through market fish consumption. J Hazard Mater 192:374-380

Wang HS, Xu WF, Chen ZJ, Cheng Z, Ge LC, Man YB, Giesy JP, Du J, Wong CKC, Wong MH (2013) In vitro estimation of exposure of Hong Kong residents to mercury and methylmercury via consumption of market fishes. J Hazard Mater 248-249:387-393 


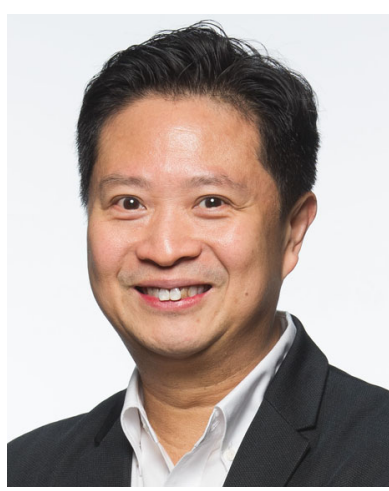

Prof KKL Yung graduated with Doctor of Philosophy degree in 1995 from the University of Oxford. He has been extremely active in professional activities for both research and education locally and international institution. Serving as a full professor in the university, he has spent considerable time in research. His expertise of research is in neurobiology, molecular biotechnology and nanomedicine, environmental science, neurotoxicology, and using biotechnology for renewable energy. He has published over 100 original research articles in SCI journals focusing on research on neurodegenerative diseases and other advanced biotechnology developments and on environmental toxicology and applications of new biotechnology to various fields including new energy. Being an Associate Head and full Professor in Department of Biology, Hong Kong Baptist University since 2005, he also served several posts such as an ex-official member of the University Research Committee, Secretary then Vice President of the Hong Kong Society of Neurosciences, Secretary of the Hong Kong Movement Disorder Society, the Financial Secretary of the Hong Kong Brain Foundation, representative of Asia Pacific region in the representative of Asia Pacific region in the Public Education Committee of International Brain Organization (IBRO), Member of Society of Neuroscience USA.

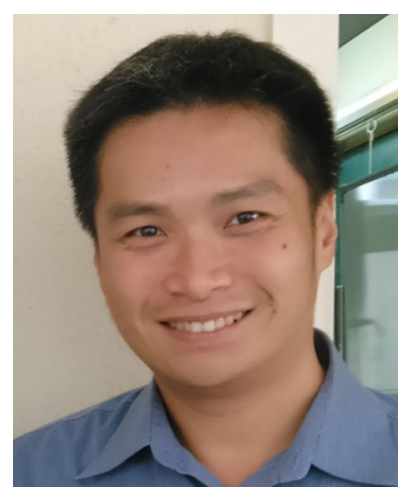

Dr. HMH Leung is an Adjunct Professor in New Jersey City University, Researcher in Hong Kong Baptist University, Lecturer in Upper Iowa University, Hong Kong Shue Yan University, The Open University of Hong Kong and Institute of Vocational Education. Since 2006, more than 40 peerreviewed articles have been published in international journals, mainly in the field of environmental sciences. Being invited by the ESPR Editor-in-Chief Philippe Garrigues, Dr. Leung has become a guest editor of international journal ESPR. Besides, Dr. Leung has been assisting several international publishers to review manuscripts for more than 10 years. Dr. Leung's scientific research includes mycorrhizoremediation such as phytoremediation, phytofiltration, phytostabilization, plant physiology, and rhizofiltration and marine biology such as biodiversity study in river and marine habitat and ecotoxicology of heavy metals and persistent organic pollutants in marine and freshwater sediment. 